\title{
Changing Vertical Nystagmus in the Opposite Direction: Is the Transition From Upbeat to Downbeat Nystagmus a Diagnostic Clue for Wernicke's Encephalopathy?
}

\section{Won Tae Yoon*}

Department of Neurology, Kangbuk Samsung Hospital, Sungkyunkwan University School of Medicine, Seoul, Republic of Korea

\begin{abstract}
Background: Changes of vertical nystagmus in the opposite direction are very rarely reported. This study aimed to report an unusual case of Wernicke's encephalopathy (WE) presenting with a transition from upbeat nystagmus (UN) to downbeat nystagmus (DN) and to investigate the clinical pattern of changing vertical nystagmus in the opposite direction reported in the literature.

Methods: We present a WE patient with primary position UN that changed to DN with an upward or horizontal lateral gaze. Additionally, we review previously reported cases and analyze the clinical patterns of changing vertical nystagmus in the opposite direction.

Results: Among 10 cases, including our case, the most common type of changing vertical nystagmus in the opposite direction was a transition from UN to $D N(n=9,90 \%)$. The most common diagnosis was WE, which is accompanied by changes in vertical nystagmus from $U N$ to $D N(n=6,60 \%)$. The most commonly associated neuro-radiological localizations for the changing of vertical nystagmus were the brainstem and the cerebellum.

Conclusion: The results of this clinical investigation may provide support for the diagnosis of WE. In addition, if young or middle-aged patients exhibit transitions from UN to DN with brainstem or cerebellar signs, a diagnosis of WE should be considered. Furthermore, clonazepam and thiamine might be helpful for improving nystagmus symptoms.
\end{abstract}

Keywords: Upbeat nystagmus; Downbeat nystagmus; Wernicke's encephalopathy; Thiamine; Clonazepam

\section{Introduction}

Vertical nystagmus (upbeat or downbeat nystagmus) is relatively rare among neurological signs. Purely vertical nystagmus is usually central in origin, but the causes of pathological vertical nystagmus are variable and include congenital and idiopathic causes. Vertical nystagmus may also be secondary to a pre-existing neurological disorder or caused using certain drugs [1]. Downbeat nystagmus (DN) is the most common form of acquired involuntary ocular oscillation overriding fixation [2]. DN may be caused by lesions of the vestibulocerebellum and, rarely by bilateral paramedian brainstem pathology $[2,3]$. The etiology of DN is diverse, and craniocervical malformations, cerebellar degeneration, vascular pathology, inflammatory disease and intoxication with lithium or antiepileptic drugs have been implicated [2,4-8]. Upbeat nystagmus (UN) is also a type of central vestibular nystagmus and is usually transient and less common than DN. UN may occur because of lesions from the medulla to the thalamus due to damage to the pathways mediating the upward vestibulo-ocular reflex (VOR) or the neural integrators involved in vertical gaze holding [9]. In view of its causative etiology, UN has also been reported in various neurological conditions including infarctions, hemorrhages, tumors, multiple sclerosis, WE, epilepsy, brainstem encephalitis, CreutzfeldtJakob disease, Behcet syndrome, meningitis, Chiari malformation, and cerebellar degeneration [9-12]

Among these signs of vertical nystagmus, the coexistence or transition of two opposite forms of vertical nystagmus are extremely rare, and changes in the direction of vertical nystagmus have been reported in only a limited number of case reports in the literature [1320]. The aim of this work is not only to report the clinically unusual phenotype of changing vertical nystagmus in the opposite direction associated with $\mathrm{WE}$, but also to review previously reported cases and to analyze clinical patterns from the literature of patients who suffered from changes in vertical nystagmus in the opposite direction.

\section{Materials and Methods}

\section{Data acquisition and patients}

Through consultation in the emergency department of my hospital, I identified one patient with changing vertical nystagmus in the opposite direction, from $\mathrm{UN}$ to $\mathrm{DN}$, which is an unusual neurologic sign that might be associated with WE. Written informed consent was obtained from the patient to study all clinical data, videotaping, and brain imaging results. The PubMed database was screened for articles related to changing vertical nystagmus in the opposite direction from 1960 to September 2017 via searches for the following terms: "changing nystagmus", "upbeat nystagmus", "up beating nystagmus", "downbeat nystagmus", and "down beating nystagmus". Screening of the PubMed database yielded 825 articles (the individually searched terms yielded 192, 177, 38, 384 and 34 articles, respectively). Among these articles, only nine cases (eight articles of case report) with changing vertical nystagmus in the opposite direction, which presented changing vertical nystagmus from $\mathrm{UN}$ to $\mathrm{DN}$ or from $\mathrm{DN}$ to $\mathrm{UN}$, were included for analysis. The inclusion criterion was as follows: reported cases presenting with changing vertical nystagmus in the opposite direction

*Corresponding author: Won Tae Yoon, Department of Neurology, Kangbuk Samsung Hospital, Sungkyunkwan University School of Medicine, Saemunan-Ro, Jongno-Gu, Seoul, Republic of Korea, Tel: 82-2-2001-1840; Fax: +82-2-20012988; E-mail: wtyoon@gmail.com

Received November 21, 2017; Accepted December 16, 2017; Published December 19, 2017

Citation: Yoon WT (2017) Changing Vertical Nystagmus in the Opposite Direction: Is the Transition From Upbeat to Downbeat Nystagmus a Diagnostic Clue for Wernicke's Encephalopathy? J Neurol Disord 5: 370. doi:10.4172/2329 6895.1000370

Copyright: () 2017 Yoon WT. This is an open-access article distributed under the terms of the Creative Commons Attribution License, which permits unrestricted use, distribution, and reproduction in any medium, provided the original author and source are credited. 
induced by central origin and/or symptomatic changing vertical nystagmus in the opposite direction presumably associated with druginduced or organic causes. Reported cases that presented with changing horizontal or torsional nystagmus with peripheral origin or changing nystagmus by unknown cause, as well as undescribed cases that focused on presumable causes and detailed neuro-radiological findings, were excluded.

\section{Statistical analysis}

The collected data were analyzed via descriptive statistics (absolute and relative frequencies). Continuous variables are expressed as means \pm standard deviations (SDs), and categorical variables are expressed as percentages.

\section{Results}

\section{Case Presentation}

A 42-year-old woman was referred to our facility due to dizziness and gait disturbance ten days prior. Nine months prior, she was admitted to another hospital due to general weakness and vomiting and was diagnosed with WE. After treatment and nutritional supportive care, her condition improved, and she was able to perform daily life activities. However, she complained of newly developed dizziness and recently aggravated gait disturbance. Her neurological examination revealed not only mild ataxic gait and postural instability but also primary position UN. Upon further neurological examinations, we also observed spontaneous primary position UN changing to DN due to an upward gaze and a bilateral horizontal gaze. In downward gaze, UN was presented as like spontaneous primary position UN. A Video Segment 1 , movie file shows this in more detail. These neuro-ophthalmologic findings were more significantly observed during the removal of fixation by the Frenzel goggles test in Video Segment 2.

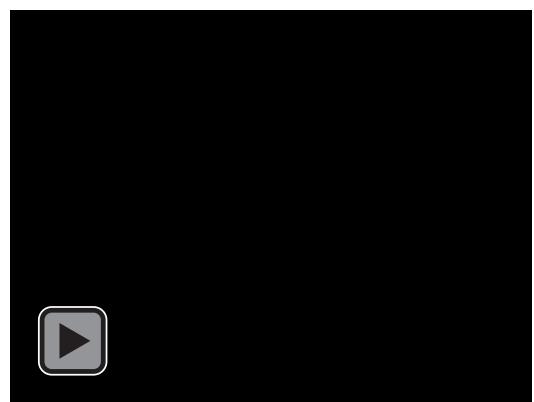

Video segment 1: The patient exhibited spontaneous upbeat nystagmus in the primary position, which changed to downbeat nystagmus with an upward gaze and a bilateral horizontal gaze.

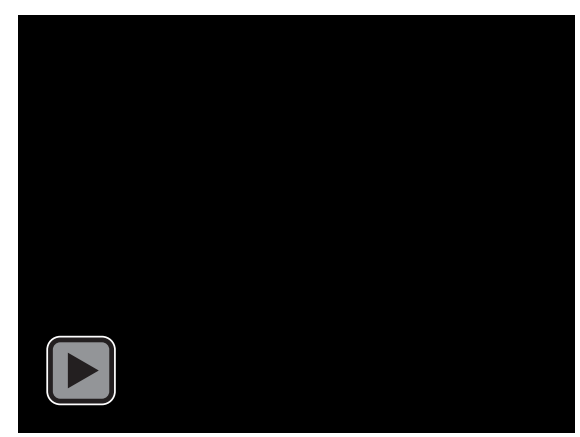

Video segment 2: When fixation was removed during the Frenzel goggles test, the neuro-ophthalmologic findings became more significant.
Routine laboratory tests were normal, and no typical neuroradiological findings of WE were present in magnetic resonance imaging (MRI), except for a mildly decreased vitamin B1 (thiamine) level (61.56 nmol/L; normal range: $66.5 \sim 200 \mathrm{nmol} / \mathrm{L})$. Thus, she was clinically diagnosed with recurrent WE. After 10 days of thiamine replacement and supportive care, the mild ataxic gait and postural instability were improved, although mild nystagmus symptoms still remained. After clonazepam therapy was added, the nystagmus symptoms also gradually improved.

\section{Clinical analysis of changing vertical nystagmus in the op- posite direction}

Including our patient and data from the reviewed literature, we identified 10 cases of clinical confirmed changing vertical nystagmus in the opposite direction and summarized the clinical profiles of the 10 cases (Table 1) [13-20].

The analyzed cases included 7 women and 3 men (mean age: $37.9 \pm$ 12.5 years; range: 21 to 61 years). The most common type of changing vertical nystagmus was a transition from $\mathrm{UN}$ to $\mathrm{DN}(\mathrm{n}=9,90 \%)$, and the reverse transition from $\mathrm{DN}$ to $\mathrm{UN}$ was observed in only one case $(n=1,10 \%)$. Among these ten cases, the most common final diagnosis was WE (or Wernicke-Korsakoff syndrome), which was uniformly associated with changing vertical nystagmus from $\mathrm{UN}$ to $\mathrm{DN}(\mathrm{n}=6$, $60 \%)$.

Among the 5 patients with documented neuro-radiological localizations, the primary neuro-radiological localizations associated with changing vertical nystagmus were the brainstem and the cerebellum (especially the cerebellum peduncle and anterior vermis).

In all 10 cases, the factors influencing the transition of vertical nystagmus at the time of onset of the change in direction were documented. Specific influencing factors varied and included convergence, a prone position, an upward or bilateral horizontal gaze and certain drugs (baclofen and 4-aminopyridine). Two patients were influenced by time without other specific factors. Although changes in the direction of vertical nystagmus occurred without a latent period in most cases, two cases involved latent periods from the initial onset of former vertical nystagmus, which lasted 8 months and one year. In only one case (our patient), the more common vertical nystagmus transition from UN to DN was observed during the Frenzel goggles test rather than by the naked eye during neurological examination.

Among the documented cases that included treatments for the transition of vertical nystagmus, the most common medication was thiamine, which was used in six cases of WE (or Wernicke-Korsakoff syndrome). In one report and our case, the addition of clonazepam was helpful for improving nystagmus symptoms.

\section{Discussion}

To date, a few cases presenting primary position vertical nystagmus changes in the opposite direction have been reported; however, to the best of our knowledge, our case is the first report in the literature of primary position UN changing to the downward direction as DN that was only influenced by upward and bilateral horizontal gaze. No clinical reports have presented changes in the direction of vertical nystagmus by videotaped, actual presentation and the Frenzel goggles test in the literature. Additionally, this study is the first to analyze the clinical patterns in the literature of patients suffering from vertical nystagmus who experienced changes in the opposite direction. Our case and an analysis of other reported cases demonstrate that the main feature of vertical nystagmus changes in the opposite direction is a transition 


\begin{tabular}{|c|c|c|c|c|c|c|}
\hline $\begin{array}{l}\text { Changing types } \\
\text { of vertical nystagmus }\end{array}$ & $\begin{array}{l}\text { Gender/Age } \\
\text { [Reference] }\end{array}$ & Final diagnosis & $\begin{array}{l}\text { Neuro-radiological } \\
\text { Localizations }\end{array}$ & $\begin{array}{l}\text { Influencing factors } \\
\text { or conditions }\end{array}$ & $\begin{array}{l}\text { Time to changing } \\
\text { of direction }\end{array}$ & $\begin{array}{l}\text { Medication } \\
\text { for treatment }\end{array}$ \\
\hline From *UN to $† D N$ & $\mathrm{~F} / 35[13]$ & $\begin{array}{l}\text { Wernicke-Kosarkoff } \\
\text { syndrome }\end{array}$ & Normal (CT) & Convergence & $\ddagger N A$ & Thiamine \\
\hline From UN to DN & $\mathrm{M} / 41[14]$ & Cerebellar atrophy & $\begin{array}{l}\text { Anterior vermis of } \\
\text { cerebellum atrophy }\end{array}$ & Prone position & NA & NA \\
\hline From UN to DN & $F / 44[14]$ & Multiple sclerosis & $\begin{array}{l}\text { Superior cerebellar } \\
\text { peduncle (Brachium } \\
\text { conjunctivum) lesions }\end{array}$ & Prone position & NA & NA \\
\hline From UN to DN & $F / 21[15]$ & $\begin{array}{l}\text { Posterior medullary } \\
\text { hemorrhage }\end{array}$ & $\begin{array}{l}\text { Posterior and medial part } \\
\text { of medulla }\end{array}$ & $\begin{array}{c}\text { Convergence } \\
\text { and downward gaze }\end{array}$ & NA & NA \\
\hline From UN to DN & $F / 24[16]$ & $\begin{array}{c}\text { Wernicke's } \\
\text { encephalopathy }\end{array}$ & Caudal brainstem lesions & The course of time & NA & NA \\
\hline From UN to DN & F/33 [17] & $\begin{array}{c}\text { Wernicke's } \\
\text { encephalopathy }\end{array}$ & Normal (MRI) & Baclofen & 12 months later & NA \\
\hline From UN to $\mathrm{DN}$ & $\mathrm{M} / 27$ [18] & $\begin{array}{c}\text { Wernicke's } \\
\text { encephalopathy }\end{array}$ & NA & The course of time & 8 months later & $\begin{array}{l}\text { Thiamine, } \\
\text { Clonazepam }\end{array}$ \\
\hline From UN to DN & $\mathrm{M} / 51[19]$ & $\begin{array}{l}\text { Wernicke's } \\
\text { encephalopathy }\end{array}$ & $\begin{array}{l}\text { Bilateral medial thalami, } \\
\text { periaqueductal gray } \\
\text { matters, and cerebellar } \\
\text { peduncles }\end{array}$ & During upward gaze & No latency & Thiamine \\
\hline From $\mathrm{DN}$ to UN & F/61 [20] & $\begin{array}{l}\text { Downbeat nystagmus } \\
\text { syndrome }\end{array}$ & Normal (MRI) & $\begin{array}{l}\text { 4-aminopyridine } \\
\text { (fampridine) }\end{array}$ & NA & $\begin{array}{l}\text { Spontaneous } \\
\text { remission }\end{array}$ \\
\hline From UN to DN & F/42 [present case] & $\begin{array}{l}\text { Wernicke's } \\
\text { encephalopathy } \\
\text { (recurrent) }\end{array}$ & Normal (MRI) & $\begin{array}{c}\text { During upward and } \\
\text { bilateral } \\
\text { horizontal gaze }\end{array}$ & No latency & $\begin{array}{l}\text { Thiamine, } \\
\text { clonazepam }\end{array}$ \\
\hline
\end{tabular}

Table 1: Summary of clinical characteristics and neuro-radiological localizations in reported cases and present case of changing of vertical nystagmus in the opposite direction.

from UN to DN. Recently, one report showed the opposite vertical nystagmus change, with a transition from downbeat to upbeat, which was transiently influenced using the drug 4-aminopyridine. Until now, changes in vertical nystagmus in the opposite direction had not been reported in the literature. Additionally, there were no reports of vertical nystagmus changing in the opposite direction induced by other causative neurologic diseases, except for WE (or Wernicke-Korsakoff syndrome), cerebellar atrophy, multiple sclerosis, posterior medullary hemorrhage, and downbeat nystagmus syndrome.

WE is an uncommon neurological complication of vitamin B1 (thiamine) deficiency characterized by the acute onset of ocular motor signs, ataxia and a confusional state. Many oculomotor disorders, including horizontal and vertical gaze paresis, which may progress to total ophthalmoplegia, have been reported in cases of WE $[21,22]$. In this study, most cases were associated with WE (including WernickeKorsakoff syndrome) regardless of the presence of neuro-radiological findings. Among the 6 patients diagnosed with WE, all were aged between their 20 s and early 50 s, and all patients presenting changing vertical nystagmus showed a transition from UN to DN. The transition from $\mathrm{UN}$ to $\mathrm{DN}$ in most patients with WE were influenced by convergence or other directional gaze (e.g., upward gaze or bilateral horizontal gaze).

Therefore, if changing vertical nystagmus with a transition from UN to DN is observed in young or middle-aged unconscious or confusional patients, a diagnosis of WE should be considered, even if there is no evidence of typical neuro-radiological findings. Furthermore, changing vertical nystagmus with a transition from $\mathrm{UN}$ to $\mathrm{DN}$ influenced by convergence or another directional gaze (e.g., upward gaze or bilateral horizontal gaze) might be a diagnostic clue for WE. As in our case, the Frenzel goggles test may be helpful for evaluating the exact status and clinical characteristics of changing vertical nystagmus, rather than general neurological examinations by the naked eye.

The pathomechanism of changing vertical nystagmus in the opposite direction has not been clearly defined. Consistent with the literature, $\mathrm{DN}$ is the most frequent form of acquired persisting fixation nystagmus, which is often caused by bilaterally impaired function of the flocculus [23,24], Similarly, UN may be associated with an underlying imbalance of the vertical VOR, and a mismatch in neural velocity-toposition integration due to a deficiency of the latter is possible $[1,25]$.

The causative mechanism of changing vertical nystagmus in the opposite direction is still a matter of debate, and several potential mechanisms have been suggested. One case report described UN due to posterior medullary hemorrhage and suggested that an underlying central vestibular imbalance may cause the transition from UN to DN [15]. A separate case report of WE showed a transition from transient $\mathrm{UN}$ to permanent $\mathrm{DN}$ over a period of months and suggested that the transition was caused by the predominant difference in vertical velocity induced by gravity [18]. Another study explained that the transition from DN to UN caused by 4 -aminopyridine may be associated with the augmentation of the physiological inhibitory influence on cerebellar nuclei neurons [20].

As in our case and a previous case report, if changing vertical nystagmus in the opposite direction is prolonged or DN persists after the transition from UN to DN, clonazepam may be helpful in reducing nystagmus symptoms. The systemic administration of clonazepam, a gamma-aminobutyric acid (GABA) agonist, may be effective in suppressing nystagmus symptoms, especially the appearance of primary position DN. In a previous case report, the authors explained that the suppressive effects of a GABA agonist on longstanding DN suggest that these abnormal eye movements are caused by a GABA inhibitory dysfunction in the central vestibular system [18]. This study had several limitations. First, patient enrollment was conducted in the small sample size. Even though statistical significance was not achieved because of small sample size, the clinical presentation of changing vertical nystagmus in the opposite direction is extremely rare and might be clue for differential diagnosis in the hospital emergency room or neuro-critical care unit. Second, the clinical data of some patients were retrospectively corrected using the PubMed database. 
Third, the relationship between changing pattern of vertical nystagmus and clinical characteristics including gender, age, final diagnosis, neuro-radiological localizations, influencing factors/conditions, time to changing of direction and medication for treatment were assessed for this study. However, other some clinical factors and neuroophthalmologic findings were not assessed in detail, which should be considered in future comprehensive studies.

\section{Conclusion}

To our knowledge, this study is the first clinical investigation of changing vertical nystagmus in the opposite direction and the first report of the transition from UN to DN by upward and bilateral horizontal gaze in a patient with WE. As in this clinical study, if the transition of nystagmus from $\mathrm{UN}$ to $\mathrm{DN}$ is accompanied by brainstem or cerebellar signs, a diagnosis of WE should be considered even if initial neuroradiological findings are presumed to be normal. Clonazepam may also be helpful as an additional symptomatic treatment in cases involving prolonged nystagmus symptoms.

\section{Conflicts of Interest}

The author has no financial or personal relations that could pose a conflict of interest.

\section{References}

1. Pierrot-Deseilligny C, Milea D (2005) Vertical nystagmus: clinical facts and hypotheses. Brain 128: 1237-1246.

2. Wagner JN, Glaser M, Brandt T, Strupp M (2008) Downbeat nystagmus: aetiology and comorbidity in 117 patients. J Neurol Neurosurg Psychiatry 79: 672-677.

3. Bertholon P, Convers P, Barral FG, Duthel R, Michel D (1993) Post-traumatic syringomyelobulbia and inferior vertical nystagmus. Rev Neurol 149: 355-358.

4. Williams DP, Troost BT, Rogers J (1988) Lithium-induced downbeat nystagmus. Arch Neurol 45: 1022-1023.

5. Chrousos GA, Cowdry R, Schuelein M, Abdul-Rahim AS, Matsuo V, et al. (1987) Two cases of downbeat nystagmus and oscillopsia associated with carbamazepine. Am J Ophthalmol 103: 221-224.

6. Halmagyi GM, Rudge P, Gresty MA, Sanders MD (1983) Downbeating nystagmus. A review of 62 cases. Arch Neurol 40: 777-784.

7. Baloh RW, Spooner JW (1981) Downbeat nystagmus: A type of central vestibular nystagmus. Neurology 31: 304-310

8. Alpert JN (1978) Downbeat nystagmus due to anticonvulsant toxicity. Ann Neurol 4: 471-473.
9. Kim JS, Yoon B, Choi KD, Oh SY, Park SH, et al. (2006) Upbeat nystagmus: Clinicoanatomical correlations in 15 patients. J Clin Neurol 2: 58-65.

10. Zingler VC, Strupp M, Jahn K, Glaser M, Herberger S, et al. (2005) Upbeat nystagmus as the initial clinical sign of Creutzfeldt-Jakob disease. Ann Neurol 57: 607-608.

11. Kumar A, Patni AH, Charbel F (2002) The Chiari I malformation and the neurotologist. Otol Neurotol 23: 727-735.

12. Zee DS, Leigh RJ (1983) Disorders of eye movements. Neurol Clin 1: 909-928.

13. Cox TA, Corbett JJ, Thompson HS, Lennarson L (1981) Upbeat nystagmus changing to downbeat nystagmus with convergence. Neurology 31: 891-892.

14. Mizuno M, Kudo Y, Yamane M (1990) Upbeat nystagmus influenced by posture: report of two cases. Auris Nasus Larynx 16: 215-221.

15. Rousseaux M, Dupard T, Lesoin F, Barbaste P, Hache JC (1991) Upbeat and downbeat nystagmus occurring successively in a patient with posterior medullary haemorrhage. J Neurol Neurosurg Psychiatry 54: 367-369.

16. Sakuma A, Kato I, Ogino S, Okada T, Takeyama I (1996) Primary position upbeat nystagmus with special reference to alteration to downbeat nystagmus. Acta Otolaryngol Suppl 522: 43-46.

17. Kastrup O, Maschke M, Keidel M, Diener HC (2004) Presumed pharmacologically induced change from upbeat- to downbeat nystagmus in a patient with Wernicke's encephalopathy. Clin Neurol Neurosurg 107: 70-72.

18. Suzuki Y, Matsuda T, Washio N, Ohtsuka K (2005) Transition from upbeat to downbeat nystagmus observed in a patient with Wernicke's encephalopathy. Jpn J Ophthalmol 49: 220-222.

19. Shin BS, Oh SY, Kim JS, Lee H, Kim EJ, et al. (2010) Upbeat nystagmus changes to downbeat nystagmus with upward gaze in a patient with Wernicke's encephalopathy. J Neurol Sci 298: 145-147.

20. Feil K, Claassen J, Bardins S, Teufel J, Habs M, et al. (2013) Transition from downbeat to upbeat nystagmus caused by 4 -aminopyridine. J Neurol 260 : 1426-1428.

21. Cogan DG, Witt ED, Goldman-Rakic PS (1985) Ocular signs in thiaminedeficient monkeys and in Wernicke's disease in humans. Arch Ophthalmol 103: 1212-1220.

22. Cogan DG, Victor M (1954) Ocular signs of Wernicke's disease. AMA Arch Ophthalmol 51: 204-211.

23. Kalla R, Glasauer S, Buttner U, Brandt T, Strupp M (2007) 4-aminopyridine restores vertical and horizontal neural integrator function in downbeat nystagmus. Brain 130: 2441-2451.

24. Kalla R, Deutschlander A, Hufner K, Stephan T, Jahn K, et al. (2006) Detection of floccular hypometabolism in downbeat nystagmus by fMRI. Neurology 66 281-283.

25. Glasauer S, Hoshi M, Kempermann U, Eggert T, Buttner U (2003) Threedimensional eye position and slow phase velocity in humans with downbeat nystagmus. J Neurophysiol 89: 338-354. 